\title{
Occurrence of $\boldsymbol{\beta}$-Alanine Betaine in the Adductor Muscle of Fan-mussel
}

\author{
Shoji Konosu and Katsuko WatanabE* \\ (Received January 9, 1973)
}

\begin{abstract}
A fairly large amount of a betaine slightly differing from glycine betaine was detected in the extract of the adductor muscle of fan-mussel, Atrina pectinata japonica. It was isolated by ion-exchange column chromatography using Dowex 50-X12, AG 50W-X12, Amberlite IRA-400, and Amberlite IRC-50 and identified as $\beta$-alanine betaine ( $\beta$-homobetaine) on the basis of elementary analysis and NMR and IR spectral studies of its hydrochloride. The isolated and synthesized specimens showed an unequivocal agreement in melting points, $\mathbf{R f}$ values in TLC, and IR spectra. The possibility of a wide distribution of the betaine in aquatic organisms is discussed.
\end{abstract}

Since $\beta$-alanine betaine ( $\beta$-homobetaine) was reported to be present in the cutaneous muscle utricle of the ascidian species by FLÖSSNER ${ }^{1)}$ in 1932, no information has been available about its distribution in aquatic animals. The authors have recently detected a fairly large amount of a betaine slightly differing from glycine betaine in the adductor muscle of fan-mussel, Atrina pectinata japonica, collected along the coast of Okayama Prefecture. The substance was isolated by ion-exchange column chromatography and finally identified as $\beta$-alanine betaine by comparing with the synthetic specimen. The present paper deals with these results.

\section{Experimental and Results}

Material and preparation of extract The fan-mussel caught along the coast of Okayama Prefecture was obtained at a fish market in Tokyo in February, 1971. The adductor muscle collected was stored in a freezer at $-20^{\circ} \mathrm{C}$ until used.

The preparation of $66 \%$ ethanolic extract from $310 \mathrm{~g}$ of the adductor muscle was carried out as described previously ${ }^{2}$. After removal of ethanol under reduced pressure, the extract was defatted with diethyl ether.

Isolation of $\beta$-alanine betaine and its properties The ion-exchange column chromatography for isolation of atrinine ${ }^{2)}$ was adopted with slight modifications.

The extract was poured onto a column of Dowex 50-X12 (H-form, 200-400 mesh, $9 \times 26 \mathrm{~cm}$ ) and developed with $1 \mathrm{~N} \mathrm{HCl}$ at a flow rate of $90 \mathrm{ml} / \mathrm{hr}$. The elution of betaines was monitored by thin layer chromatography (TLC) with cellulose plate (Avicel SF) and a mixture of $95 \%$ ethanol and $28 \%$ ammonium hydroxide $(85: 15, \mathrm{v} / \mathrm{v})$. The spots were

* Laboratory of Marine Biochemistry, Faculty of Agriculture, The University of Tokyo, Bunkyo-ku,

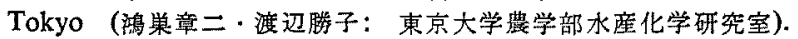


visualized by spraying with the Dragendorff reagent. Most of $\beta$-alanine betaine was eluted between 13.5 and 15.0 liters, but contaminated with glycine betaine. This fraction was evaporated to dryness in vacuo and the residue dissolved in a small amount of water. The solution was introduced to a column of AG 50W-X12 (H-form, 200-400 mesh, $3 \times 60 \mathrm{~cm}$ ) and $1 \mathrm{~N} \mathrm{HCl}$ was allowed to flow through it at a rate of $50 \mathrm{ml} / \mathrm{hr}$. $\beta$-Alanine betaine appearing between 2.3 and 2.7 liters was separated almost completely from glycine betaine, which was eluted immediately after $\beta$-alaine betaine. From the fractions containing $\beta$-alanine betaine, the excess $\mathrm{HCl}$ was removed in vacuo and the residue taken up in a small amount of water. The aqueous solution was then passed through successive connected columns of Amberlite IRA-400 (OH-form, $12 \mathrm{ml}$ ) and Amberlite IRC-50 $(\mathrm{H}$-form, $20 \mathrm{ml})$ to remove a trace amount of ninhydrin-positive substances. The columns were washed with water and the percolate combined with washings was acidified with $1 \mathrm{~N}$ $\mathrm{HCl}$. On evaporating the solution under reduced pressure, crystals of $\beta$-alanine betaine hydrochloride appeared instantly. By recrystallizing twice from $95 \%$ ethanol, $29 \mathrm{mg}$ of thin plates was obtained; mp. $197-198^{\circ} \mathrm{C}$. Anal. Found: C, 42.95; H, 8.34; N, $8.64 \%$. Calcd. for $\mathrm{C}_{6} \mathrm{H}_{14} \mathrm{NO}_{2} \mathrm{Cl}: \mathrm{C}, 42.99 ; \mathrm{H}, 8.42 ; \mathrm{N}, 8.36 \%$. The second crop (28 $\mathrm{mg}$ ) was collected from the filtrates.

The hydrochloride gave a slightly brownish orange color with the Dragendorff reagent and was negative to ninhydrin. NMR at $100 \mathrm{MHz}$ in deuterium oxide using DSS as an internal reference: $2.94 \mathrm{ppm}(2 \mathrm{H}$, triplet $), 3.12 \mathrm{ppm}(9 \mathrm{H}$, singlet), $3.64 \mathrm{ppm}(2 \mathrm{H}$, triplet). IR (KBr): $\nu_{\mathrm{C}=0} 1720 \mathrm{~cm}^{-1}$ (Fig. 1). The picrate was prepared from the hydrochloride and obtained as yellow needles; mp. $171-172^{\circ} \mathrm{C}$. Anal. Found: C, 39.94; H, $4.40 ; \mathrm{N}, 15.62 \%$. Calcd. for $\mathrm{C}_{22} \mathrm{H}_{10} \mathrm{~N}_{4} \mathrm{O}_{9}: \mathrm{C}, 40.00 ; \mathrm{H}, 4.48 ; \mathrm{N}, 15.55 \%$.

These results strongly indicate that the isolated substance is $\beta$-alanine betaine.

Comparison of isolated and synthesized $\beta$-alanine betaine specimens $\beta$-Alanine betaine was synthesized from $\beta$-bromopropionic acid and trimethylamine after UTSUNOMIYA ${ }^{3)}$. The hydrochloride was obtained as thin plates; mp. $198^{\circ} \mathrm{C}$ (reported, $195-196^{\circ} \mathrm{C}^{4}$ ). Anal. Found: $\mathrm{C}, 43.05 ; \mathrm{H}, 8.54 ; \mathrm{N}, 8.17 \%$. Calcd. for $\mathrm{C}_{6} \mathrm{H}_{14} \mathrm{NO}_{2} \mathrm{Cl}: \mathrm{C}, 42.99 ; \mathrm{H}, 8.42 ; \mathrm{N}$, $8.36 \%$. The picrate was obtained as yellow needles; mp. $171-172^{\circ} \mathrm{C}$ (reported, 168 $\left.169^{\circ} \mathrm{C}^{31}\right)$. Anal. Found: $\mathrm{C}, 39.84 ; \mathrm{H}, 4.41 ; \mathrm{N}, 15.58 \%$. Calcd. for $\mathrm{C}_{12} \mathrm{H}_{16} \mathrm{~N}_{4} \mathrm{O}_{9}: \mathrm{C}, 40.00$;

Table 1. Rf values of isolated and synthesized $\beta$-alanine betaine hydrochlorides in thin layer chromatography.

\begin{tabular}{clcc}
\hline & \multicolumn{1}{c}{ Condition* } & Isolated & Synthesized \\
\hline Cellulose, & $95 \%$ ethanol-28\% ammonium hydroxide $(85: 15)$ & 0.22 & 0.22 \\
",$\quad n$-butanol-acetic acid-water $(100: 30: 85)$ & 0.49 & 0.49 \\
Kieselgel G, methanol-28\% ammonium hydroxide $(75: 25)$ & 0.36 & 0.36 \\
$"$, methanol-acetone-35\% hydrochloric acid $(90: 10: 10)$ & 0.42 & 0.42 \\
\hline
\end{tabular}

* The compositions of solvents are given in $v / v$. 
$\mathrm{H}, 4.48 ; \mathrm{N}, 15.55 \%$.

The hydrochlorides of isolated and synthesized specimens gave the same $\mathrm{Rf}$ values in TLC (Table 1) and identical IR spectra (Fig. 1). No depression of melting points was observed on admixture of isolated and synthesized substances both in hydrochloride and picrate forms.

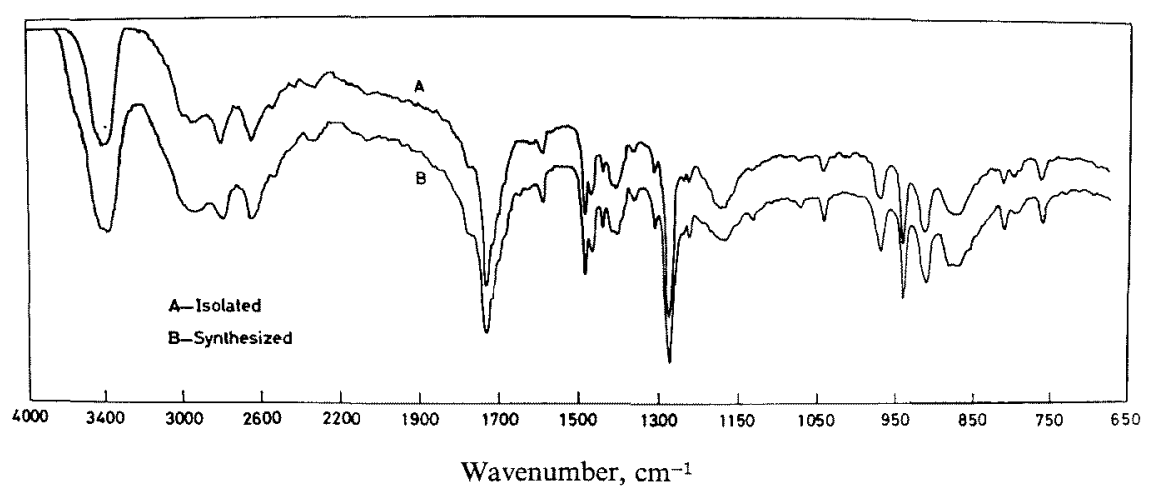

Fig. 1. IR spectra of isolated and synthesized $\beta$-alanine betaine hydrochlorides $(\mathrm{KBr})$.

\section{Discussion}

The occurrence of a fairly large amount of $\beta$-alanine betaine in the adductor muscle of fan-mussel was confirmed. ABE and KANEDA* detected it in two species of seaweed, Monostroma nitidum and Ulva pertusa. Recently, they have recognized it also in the oyster (personal communication). These findings may suggest a rather wide distribution of this compound in marine biota, although it was not found by BEERS ${ }^{5)}$, who analyzed semiquantitatively the quaternary ammonium bases in a variety of aquatic invertebrates by paper chromatography.

Glycine betaine and $\beta$-alanine betaine are very similar in chemical properties; they behaved similarly on ion-exchangers as described above and were precipitated together by ammonium reineckate in acidic medium. It is therefore reasonably considered that $\beta$-alanine betaine might have been overlooked in determination of betaines so far conducted on aquatic organisms and the data especially on glycine betaine should be reviewed.

It is noteworthy that the adductor muscle of fan-mussel contains various betaines, such as carnitine, atrinine ${ }^{2)}$, glycine betaine, and $\beta$-alaine betaine. A quantitative analysis of these betaines is now under study.

* Abstracts of Papers, Ann. Meeting of Japan. Soc. Sci. Fish., Tokyo, April (1972); Kochi, October (1972). 


\section{References}

1) O. Flössner: Sitzber. Ges. Beford. ges. Naturw. Marburg, 67, 1-10 (1932).

2) S. Konosu, Y.-N. Chen, and K. Watanabe: This Bull., 36, 940-944 (1970).

3) Y. Utsunomiya: J. Pharm. Soc. Japan, 87, 1422-1424 (1967).

4) R. WILLSTÄTtER: Ber., 35, 584-620 (1902).

5) J. R. BeErs: Comp. Biochem. Physiol., 21, 11-21 (1967). 